\title{
Self-medication with antibiotics and knowledge about antibiotic resistance among nursing practitioners at a tertiary hospital in Northern Ghana: a cross-sectional survey study
}

Ismael Niadawe Issaka ( $\sim$ niadawe@gmail.com )

University of Southern Denmark: Syddansk Universitet https://orcid.org/0000-0002-2774-0629

\section{Research Article}

Keywords: self-medication, antibiotics, antibiotic resistance, nurses, Ghana

Posted Date: June 28th, 2021

DOI: https://doi.org/10.21203/rs.3.rs-659723/v1

License: (c) (i) This work is licensed under a Creative Commons Attribution 4.0 International License. Read Full License 


\section{Abstract \\ Background}

Antimicrobial resistance attributed to self-medication with antibiotics is a growing global health concern. Even among health-aware subgroups including medical and nursing practitioners, the prevalence of selfmedication with antibiotics remains high. In Ghana, the extent of self-medication with antibiotics among health professionals is not yet fully known. This study draws from a primary cross-sectional study within a tertiary medical facility in Ghana to provide a first estimate of the proportion of nurses who had selfmedicated with antibiotics within the last 12 months or longer at the time of the study. The primary study investigated associations between self-medication with antibiotics and socio-demographics, knowledge levels, perceived susceptibility, and perceived severity regarding antibiotic resistance- related conditions.

\section{Methods}

Cross-sectional survey design supported by a pre-tested, standardized, self-administered questionnaire was used to collect data among 170 nurses. Descriptive statistics was used to analyse variable distributions. Chisquare test was used for univariate analysis and logistic regression for multivariable analysis. A level of $p$ $<.05$ was considered significant. IBM Statistical Package for the Social Sciences (SPSS) version 21 was used for data analysis.

\section{Results}

$77.1 \%$ of study participants recalled having practised self-medication with antibiotics within the last 12 months and longer. $72.9 \%$ of respondents obtained antibiotics from the medical store or pharmacy. In the multivariable logistic regression analysis, years of work $\leq 5$ years $(\mathrm{OR}=0.21,95 \% \mathrm{Cl}: 0.061-0.708)$, knowledge of antibiotic resistance $(\mathrm{OR}=0.178,95 \% \mathrm{Cl}: 0.060-0.528)$, and high perceived personal severity of a disease related to antibiotic resistance $(\mathrm{OR}=0.128,95 \% \mathrm{Cl}: 0.046-0.357)$ were found significantly associated with the practice of self-medication with antibiotics.

\section{Conclusion}

To curb inappropriate use of antibiotics that increases the risk of antibiotic resistance, there is the need to promote education among nurses and stronger enforcement of laws which forbid sales without prescription.

\section{Background}

Antibiotics continue to alleviate health burden especially in low-and middle-income countries (LMICs) where bacterial infections are prevalent and a common cause of mortality. However, there is an emergence of antibiotic resistance (ABR) which presents a great public health concern. Presently, ABR is one of the biggest threats to global health, food security and development. It directly and indirectly undermines 15 out of the 17 
United Nations Sustainable Development Goals (SDG) and threatens the achievement of the Universal Health Coverage. Globally, an estimated 700,000 people die annually from untreatable infections due to the spread and emergence of antibiotic resistance. The number of deaths is projected to reach 10 million by 2050 with huge socio-economic consequences. Today, the effects of antibiotic resistance are evident in all countries regardless of income status but are greatest in LMICs where the healthcare systems are not fully advanced.

Research evidence shows that self-medication with antibiotics is a leading cause of antibiotic resistance. According to the World Health Organization (WHO), self-medication is defined as "the selection and use of medicines by individuals to treat self-recognized illnesses or symptoms". Evidence from LMICs shows that self-medication with antibiotics is driven by poor healthcare systems, weak regulation of antibiotics purchase, improper prescription and poor dispensing practices among health workers as well as nonadherence to guidelines for antibiotics dispensing. Although Self-medication is inappropriate, it is an essential component of health care and can be beneficial in various aspects. Self-medication, in general, has a positive impact on both individual health and healthcare systems. The practice provides a cheap, rapid, and convenient solution for mild illnesses, thereby reducing the burden of demand on limited healthcare systems, particularly in LMICs. However, self-medication practice is of great public health concern due to the systematic exposure of individuals and communities to antibiotic resistance. Self-medication can lead to inappropriate medicine use which predisposes patients to drug interactions, development of multi-drug resistant bacteria and difficulties in diagnosing different diseases. The practice could also lead to health risks due to masking of diseases, delays in seeking medical advice, and development of antibiotic related side effects. Inappropriate use of antibiotics is often manifested in inadequate dose, shorter duration of treatment, withdrawal of treatment when symptoms subside, and sharing of medicines with others. Self-medication is a cross-cutting driver of antibiotics resistance in both developed and developing countries. A study conducted in the United States of America (USA) revealed that self-medication with antibiotics is a common practice for treating fever, respiratory and gastrointestinal conditions among Hispanic households. In Eastern and Southern Europe, it is estimated that $20 \%-30 \%$ of antibiotics are consumed without prescription while in LMICs the consumption of antibiotics without prescription is estimated to range from $8.1 \%-93 \%$. In Ghana, a cross-sectional study of undergraduate students showed $70 \%$ prevalence of antibiotic self-medication among respondents. Studies have also reported that a third of patients had taken antibiotics prior to consultation with a doctor and in the rural community, 32\% of respondents have been reported to have used antibiotics without prescription. Similarly, prevalence of self-medication with antibiotics have been reported in other countries. For example, in Zambia (71\%), Nigeria (82.2\%) and Saudi Arabia (34\%). The availability of antibiotics via over the counter (OTC) purchase in many countries has escalated antibiotic self-medication practices. In general, antibiotics are easily purchased via OTC in LMICs compared to High-income Countries (HICs) where strict regulations apply for the use of antibiotics in patients.

Studies from Asia and Africa show that even in subgroups assumed to be more aware of the problem of antibiotic resistance such as health professionals, the prevalence of antibiotic self-medication remains high . In India, for instance, the prevalence of self-medication was found to be $67.6 \%$ among a cross-section of nurses in Mumbai. While in Ethiopia, $42 \%$ of nurses were found to have used antibiotics without prescription. Studies have also reported a relatively high prevalence of self-medication among nursing students creating public health concern as this might predispose them to future practices. Among other health professionals 
such as physicians, self-medication is even very common and vary widely. Several factors including time constraint, issues of privacy and confidentiality, and professional exposure to medicines and expert knowledge about the treatment of various diseases have been reported to contribute to self-medication among health professionals. In Ghana, the extent of antibiotic self-medication practices among nurses is not yet fully known.

The study aimed to provide a first estimate of the proportion of nurses who had ever self-medicated with an antibiotic and working in a tertiary hospital in Northern Ghana. The study further seeks to determine sociodemographic differences, in particular the role of gender, age, years of work, professional rank, and health insurance in antibiotic self-medication among hospital nurses, and to investigate the role of knowledge and perceptions about antibiotic resistance for self-medication.

\section{Methods}

\section{Study setting and study design}

The study used a cross-sectional survey design conducted at the Tamale Teaching Hospital of the Northern regional capital of Tamale, Ghana. The study population consisted of nurses working at the Tamale Teaching Hospital of Northern Ghana. Self-administered standardized questionnaires were used to collect data from nurses who were working at Tamale Teaching Hospital within the period of $17^{\text {th }}$ to $3^{\text {rd }}$ of March 2020. The Tamale Teaching Hospital is a 400-bed capacity hospital which serves the Ghanaian population as well as some neighboring countries to the north of Ghana. Since its initial establishment in 1974 as a regional hospital, Tamale Teaching Hospital has provided various health care services to the people. In 2005 it was upgraded to a teaching hospital in line with the training of health professionals from the University for Development Studies (UDS) in medicine, nursing, and nutrition. The hospital was selected as it is the largest with high population of health professionals including nurses compared to other hospitals in the region.

\section{Respondent Inclusion-exclusion criteria}

All nurses working at the Tamale Teaching Hospital, independent of gender, age, years of working experience or department they are employed were included in the study. Nurses who were available at the hospital departments during the data collection period and willing to fill the self-administered questionnaires were included in the study. However, nurses who were not willing to participate in the study or fill the questionnaires were excluded.

\section{Sample size and Sampling Technique}

Sample size was determined by using Single Proportion Formula[1], as follows:

$$
\begin{aligned}
n=Z^{2} \frac{\text { PQ }}{D^{2}} \text { where, } \quad & \mathbf{Z} \text { is estimated at } 1.96 \text { for a } 95 \% \text { confidence level, } \\
& \mathbf{P} \text { is } 84 \% \text { of the estimated prevalence }{ }^{32} \\
& \mathbf{D} \text { is the level of acceptable error estimated at } 5 \%
\end{aligned}
$$


$10 \%$ non-response rate was considered to make adjustment to the sample size population and the sample size was calculated to be 226 .

\section{Data collection process and Technique}

The data for the study was collected at various departments within Tamale Teaching Hospital where a paperpencil version of the questionnaire was handed to the nurses. Data collection was carried out by the principal investigator at the time nurses were at post at the various departments. Completed questionnaires were collected at the close of work via a slit box placed in the nurses' staff common room at the various department. This was done to guarantee anonymity, which was important to avoid a possibility of giving responses based on social desirability. Estimated time for completion of questionnaire was 15 minutes. There was no incentive for the nurses to participate in the study.

\section{Data collection instrument}

A pre-tested, standardized self-administered English-based questionnaire (Additional file 1) was used to collect data. English language was used because it is the official language of communication in the study zone. The questionnaire was developed after reviewing relevant literature and adapting parts of a standardized questionnaire for assessing self-medication with antibiotics in a Multi-Country Public Awareness Survey[1]. The 28-item self-administered questionnaire was used to collect information under 4 sections. The first included socio-demographic characteristics and general information data such as age, sex, rank, household composition and duration of work after graduation from nursing school and health insurance status. The second section comprised self-medication practices including frequency of antibiotics used, reasons for self-medication, type of antibiotics used in self-medication, sources of self-medicating antibiotics and disease conditions for self-medication. Under this section, respondents were also asked to respond to the last time (within the last 12 months and above) they took an antibiotic without a prescription. The third section of the questionnaire collected information on knowledge of antibiotic resistance among nurses. In this section of the questionnaire, respondents were required to answer (true/false) questions relating to knowledge of antibiotic resistance, inappropriate prescription practices, infection prevention and control practices and management of a patient with antibiotic resistance.

The fourth section of the questionnaire was used to collect information on a respondent's perceived personal susceptibility (likelihood) of developing a condition with antibiotic resistance and the perceived severity of such a condition. A 7-point scale was used to collect information about perceived personal susceptibility ranging from 1 (highly unlikely) to 7 (highly likely). Questions on perceived severity used 3-point scale response options from not severe at all to very severe.

\section{Ethical Approval and Consent to participate}

The study was conducted in accordance with the Helsinki Declaration of 1964 and its later amendments. Ethical clearance was obtained from the Department of Research and Development of the Tamale Teaching 
Hospital where the study was carried out with reference number TTH/R\&D/SR/012. Prior to obtaining the ethical clearance, a formal letter was written to the hospital by the principal investigator requesting permission to conduct the study. A cover letter which explained the purpose of the study, and which contained an explicit statement of consent for participation was included in the questionnaire. The letter explained that participation in the study was completely voluntary, and that consent could be withdrawn at any point in time. Data collection and storage were carried out in an anonymous/pseudonymous way, i.e., without the collection of names.

\section{Data processing and Analysis}

Descriptive statistics was used to analyze the variable distributions. Chi-square tests was used for univariate analysis and logistic regression for multivariable analysis. A level of $p<.05$ was considered significant. Data was coded and entered in Microsoft Excel Spread Sheet and analyzed using IBM Statistical Package for the Social Sciences (SPSS) version 21. Data was subsequently presented as frequency distributions and graphical summaries where appropriate.

The variables with more than two levels were recoded into dichotomous variables. Twelve key questions were used to gather information relating to respondents' knowledge about antibiotic resistance. Questions that were answered correctly were assigned a score of 1 while incorrectly answered questions were scored 0 . A total score of each respondent was then computed in addition to the mean score of respondents. Respondents with knowledge score $\leq 8$ were categorised as having a low level of knowledge while respondents with knowledge score $>8$ were categorised as having a high level of knowledge. Few missing values were noted during data analysis and per the default setting in SPSS, the missing values were automatically excluded from the analysis.

\section{Results}

Socio-demographic characteristics

As shown in Table 1, a total of 226 nurses were contacted, and 170 of them returned the questionnaire, resulting in a response rate of $75.2 \%$. Among the 170 respondents, about half were females. Majority (62.4\%) of study participants were in the age group 25-34 age group. Most of the respondents were Staff nurses (47.1\%). About half of the respondents had worked at the hospital for more than three years. Almost all participants (97\%) had health insurance from the national health scheme (see Table 1). 
Table 1

Socio-demographics and general characteristics of respondents $(n=170)$

\begin{tabular}{|c|c|c|}
\hline Variables & $\mathbf{n}$ & $\%$ \\
\hline \multicolumn{3}{|l|}{ Gender } \\
\hline Male & 84 & 49.4 \\
\hline Female & 86 & 50.6 \\
\hline Total & 170 & 100 \\
\hline \multicolumn{3}{|l|}{ Age } \\
\hline $18-24$ & 25 & 14.7 \\
\hline $25-34$ & 106 & 62.4 \\
\hline $35-44$ & 26 & 15.3 \\
\hline $45-54$ & 13 & 7.6 \\
\hline Total & 170 & 100 \\
\hline \multicolumn{3}{|l|}{ Professional rank } \\
\hline Staff Nurse & 80 & 47.1 \\
\hline Senior Staff Nurse & 34 & 20 \\
\hline Nursing Officer & 33 & 19.4 \\
\hline Senior Nursing Officer & 8 & 4.7 \\
\hline Principal Nursing & 15 & 8.8 \\
\hline Total & 170 & 100 \\
\hline \multicolumn{3}{|l|}{ Years of working as a nurse } \\
\hline Less than 3 years & 81 & 47.6 \\
\hline 3 to under 5 years & 34 & 20 \\
\hline 5 to 10 years & 46 & 27.1 \\
\hline More than 10 years & 9 & 5.3 \\
\hline Total & 170 & 100 \\
\hline \multicolumn{3}{|l|}{ Household composition } \\
\hline Single adult only & 67 & 39.4 \\
\hline Single adult and at least 1 child under 16 & 38 & 22.4 \\
\hline Married / domestic partnership - adults only & 14 & 8.2 \\
\hline Married / domestic partnership and at least 1 child under 16 & 44 & 25.9 \\
\hline
\end{tabular}




\begin{tabular}{|lll|}
\hline Variables & $\mathbf{n}$ & $\%$ \\
\hline Multiple adults aged 16 + and at least 1 child under 16 & 7 & 4.1 \\
\hline Total & 170 & 100 \\
\hline Health insurance & & \\
\hline Yes & 165 & 97 \\
\hline No & 5 & 3 \\
\hline Ever managed resistant infections & & \\
\hline Yes & 89 & 52 \\
\hline No & 81 & 48 \\
\hline Total & 170 & 100 \\
\hline
\end{tabular}

Self-medication practices

$77.1 \%$ of respondents had ever taken an antibiotic without a prescription from a medical doctor. $27 \%$ reported they had done so within the preceding 12 months (Fig. 1). Familiarity with disease conditions (43.5\%) and non-severity of disease $(25.9 \%)$ were the main reasons behind self-medication behaviour among the study participants (Table 2).

Figure 1. Last time of self-medication with antibiotics (\%)

Table 2

Reasons for antibiotic self-medication (Note: multiple answers were possible)

\begin{tabular}{|lll|}
\hline Reason & $\begin{array}{l}\text { Frequency } \\
\text { (n=131) }\end{array}$ & $\begin{array}{l}\text { Percentage } \\
\text { (\%) }\end{array}$ \\
\hline I had a busy schedule at work & 24 & 14.1 \\
\hline I am familiar with the disease condition and knew what to treat it with & 74 & 43.5 \\
\hline The condition was not severe, so it did not require consultation with a doctor & 44 & 25.9 \\
\hline I did not want my colleagues to know I was sick & 8 & 4.7 \\
\hline Due to long waiting time at consultation with a doctor & 22 & 12.9 \\
\hline Due to high cost of consultation and treatment & 9 & 5.3 \\
\hline Other reason; please, write which & 0 & 0 \\
\hline
\end{tabular}

Indications and category of antibiotics used in self-medication

The most common disease condition for the option to self-medicate was abdominal pain (31.2\%) followed by genito-urinary tract symptoms $(26.5 \%)$ and diarrhoea $(25.9 \%)$ and cough $(24.1 \%)$. Ciprofloxacin $(38.9 \%)$ 
and metronidazole (35.9\%) were the most used categories of antibiotics for self-medication among the study participants. Majority of respondents $(72.9 \%)$ obtained antibiotics from the medical store or pharmacy and only a few (3.5\%) got theirs from a colleague nurse (Table 3$)$. 
Table 3

Category of antibiotics, source, and indications of use in self-medication (multiple answers were possible) Antibiotics

Frequency $(n=$ 131)

Ampicillin

Amoxicillin

Ciprofloxacin

Amoxicillin/Clavulanic acid

Doxycycline

Co-trimoxazole

Metronidazole

Erythromycin

Flucloxacillin

Azithromycin

Ceftriaxone

Chloramphenicol

Cefuroxime

I can't remember

Disease conditions for self-medication

Cold

Diarrhoea

Flu

Cough

Fever

Menstrual cramps

Abdominal pain

Sore throat

Body pains

Genitourinary tract symptoms

Skin conditions

Can't remember
8

26

65

12

4

7

61

3

19

7

22

1

21

7

19

44

1

41

17

6

53

5

18

45

14

12
(\%)

4.7

15.3

38.2

7.1

2.4

4.1

35.9

1.7

11.2

4.1

12.9

0.6

12.4

4.1

11.2

25.9

0.6

24.1

10

3.5

31.2

2.9

10.6

26.5

8.2

7.1 


\begin{tabular}{|lll|}
\hline Antibiotics & $\begin{array}{l}\text { Frequency }(n= \\
\mathbf{1 3 1})\end{array}$ & $\begin{array}{l}\text { Percentage } \\
(\%)\end{array}$ \\
\hline Sources of antibiotics & & 72.9 \\
\hline From the medical store or pharmacy & 124 & 0.6 \\
\hline I had them saved up from a previous time & 1 & 3.5 \\
\hline From a colleague nurse & 6 & 0 \\
\hline $\begin{array}{l}\text { From doctor without formal consultation and laboratory } \\
\text { sensitivity test }\end{array}$ & 0 & 0 \\
\hline From a market stall & 0 & 0 \\
\hline From a family member or friend & 0 & 0 \\
\hline Other: please specify - & 0 & \\
\hline
\end{tabular}

Level of knowledge of antibiotic resistance among respondents

The majority $(96.2 \%)$ of respondents correctly answered that self-medication could lead to the development of antibiotic resistance and almost all the respondents also correctly answered that inappropriate prescription practices could result in bacterial resistance. Regarding knowledge about infection prevention and control practices, less than half $(46 \%)$ of respondents have knowledge that improper handwashing before and after patient contact could promote antibiotic resistance (Table 4). Overall, only $40.6 \%$ of study participants have high knowledge of antibiotic resistance (see Fig. 2).

Figure 2. Level of knowledge about antibiotic resistance among respondents $(\%),(n=167)$ 
Table 4

Level of agreement on the knowledge of antibiotics among respondents $(n=170)$

\section{Variable}

Respondents Respondents

True (\%)

\section{Appropriate practices}

Self-medication with antibiotics can lead to the development of antibiotic resistance (True/False)

Inappropriate prescription practices can lead to antibiotic resistance (True/False)

$167(98.2)$

$169(99.4)$

\section{Infection prevention and control}

Improper disposal of hospital waste can lead to antibiotic resistance (True/False)

Improper handwashing before and after patient contact can lead to antibiotic resistance (True/False)

$71(41.8)$

$99(58.2)$

\section{Knowledge of antibiotics}

Antibiotic resistance occurs when your body becomes resistant to antibiotics and they no longer work well (True/False)

$169(99.4) \quad 1(0.6)$

Many infections are becoming increasingly resistant to treatment by antibiotics (True/False)

$161(94.7) \quad 9(5.3)$

If bacteria are resistant to antibiotics, it can be very difficult or impossible to treat the infections they cause (True/False)

Antibiotic resistance is an issue that could affect me or my family (True/False)

$79(46.5)$

$91(53.5)$

Antibiotic resistance is an issue in other countries but not here (True/False)

$161(94.7) \quad 9(5.3)$

Antibiotic resistance is only a problem for people who take antibiotics regularly (True/False)

$158(92.9) \quad 12(7.1)$

Bacteria which are resistant to antibiotics can be spread from person to person (True/False)

Antibiotic-resistant infections could make medical procedures like surgery, organ transplants and cancer treatment much more dangerous $49(28.8)$

$121(71.2)$ (True/False)

Note: correct responses (True/False) are italicised in bold

Perceived likelihood of developing a condition with antibiotic resistance

The study found out that just a little over half (52\%) of respondents have ever managed a patient with a condition of antibiotic resistance. Regarding the likelihood of developing a condition with antibiotic resistance among respondents, $21.2 \%$ believed it to be unlikely while $14.7 \%$ think it is highly likely (Fig. 3 ). 
About $46 \%$ of respondents perceived a condition with antibiotic resistance to be very severe compared to $28.2 \%$ who believe that such a condition would not be severe at all (Fig. 4).

Figure 3. Likelihood of developing condition with antibiotic resistance

Figure 4. Severity of developing a condition with antibiotic resistance

Factors associated with self-medication with antibiotics

The study found that age $(x 2=7.72 ; p=0.021)$, work duration $(x 2=6.19, p=0.013)$, knowledge of antibiotic resistance $(X 2=13.22, p=0.000)$ and perceived severity of a disease associated with antibiotic resistance $(x 2=16.53, p=0.000)$ were significantly associated with self-medication with antibiotics. Respondents with age group 25-34 years, years of work $\leq 5$ years, low level of knowledge and low severity of a disease were found to practice self- medication more respectively. Further, perceived susceptibility for a disease associated with antibiotic resistance was tendentially associated with self-medication at a significance level of $p<.15$ $(x 2=3.06, p=0.142)$. There were no associations between gender and self-medication with antibiotics, and neither were professional rank, health insurance status, household composition and ever having managed resistant infections as a nurse significantly associated with self-medication (Table 5). 
Table 5

Factors influencing self-medication with antibiotics among respondents (\%)

\begin{tabular}{|c|c|c|c|}
\hline \multirow{2}{*}{$\begin{array}{l}\text { Variables } \\
\text { Gender }\end{array}$} & \multicolumn{2}{|l|}{ Self-medication } & \multirow[t]{2}{*}{ p-value } \\
\hline & Yes $(n=131)$ & No $(n=39)$ & \\
\hline Male & $65(77.4)$ & $19(22.6)$ & \\
\hline \multirow[t]{2}{*}{ female } & $66(76.7)$ & $20(23.3)$ & \\
\hline & & & 0.92 \\
\hline \multicolumn{4}{|l|}{ Age (years) } \\
\hline $18-24$ & $17(68.0)$ & $8(32.0)$ & \\
\hline $25-34$ & $89(84.0)$ & $17(16.0)$ & \\
\hline $35-44$ & 15(57.7) & $11(42.3)$ & \\
\hline \multirow[t]{2}{*}{$44-55$} & 10(76.9) & $3(23.1)$ & \\
\hline & & & 0.021 \\
\hline \multicolumn{4}{|c|}{ Nurses professional rank } \\
\hline Lower rank & $112(76.2)$ & $35(23.0)$ & \\
\hline \multirow[t]{2}{*}{ Higher rank } & 19(82.6) & $4(17.4)$ & \\
\hline & & & 0.490 \\
\hline \multicolumn{4}{|c|}{ Years of working as a nurse } \\
\hline$\leq 5$ years & $95(82.6)$ & $20(17.4)$ & \\
\hline \multirow[t]{2}{*}{$>5$ years } & $36(65.5)$ & $19(34.5)$ & \\
\hline & & & 0.013 \\
\hline \multicolumn{4}{|c|}{ Household composition } \\
\hline Living alone & $50(74.6)$ & $17(24.4)$ & \\
\hline \multirow[t]{2}{*}{ Living with others } & $81(78.6)$ & $22(21.4)$ & \\
\hline & & & 0.543 \\
\hline \multicolumn{4}{|l|}{ Health insurance } \\
\hline Yes & 128 (77.6) & $37(22.4)$ & \\
\hline \multirow[t]{2}{*}{ No } & $3(60.0)$ & $2(40.0)$ & \\
\hline & & & 0.357 \\
\hline
\end{tabular}

Notes: $\mathrm{p}$-value $<0.05$ was considered significantly associated; $A B R=$ antibiotic resistance; $*=3$ missing values 
Variables

\section{Experience managing ABR patient}

$\begin{array}{lll}\text { Yes } & 72(80.9) & 17(19.1) \\ \text { No } & 59(72.8) & 22(27.2)\end{array}$

p-value

Self-medication

0.212

\section{Knowledge of $A B R^{*}$}

High level of knowledge

$66(67.3)$

32(32.7)

Low level of knowledge

$63(91.3)$

$6(8.7)$

0.000

\section{Perceived susceptibility of ABR}

Low susceptibility

77(73.3)

28(26.7)

High susceptibility

$54(83.1)$

11(16.9)

0.142

\section{Perceived severity of disease with ABR}

$\begin{array}{lll}\text { Low severity } & 82(89.1) & 10(10.9) \\ \text { High severity } & 49(62.8) & 29(37.2)\end{array}$

0.000

Notes: $\mathrm{p}$-value $<0.05$ was considered significantly associated; $A B R=$ antibiotic resistance; $*=3$ missing values

The multivariable logistic regression model contained all variables which in the bivariate analysis had shown significant $(p<.05)$ or tendentially significant $(p<.15)$ associations with the outcome.

After adjusting for all other variables, the analysis showed that compared to the reference group of the oldest nurses (44-54), the odds of practicing self-medication with antibiotics among nurses in the age group 18-24 years was lower $(\mathrm{OR}=0.38,95 \% \mathrm{Cl}: 0.127-1.178)$.

Regarding years of work, the odds of practicing self-medication was found to be significantly lower among respondents who had more than 5 years of work experience or less ( $O R=0.21,95 \% \mathrm{Cl}: 0.061-0.708)$ than those of nurses with five years or less work experience.

Another significant association was found with knowledge of antibiotic resistance. Thus, the odds of practicing self-medication among study participants with a higher level of knowledge about antibiotic resistance was lower $(\mathrm{OR}=0.178,95 \% \mathrm{Cl}: 0.060-0.528)$ compared to participants with a lower level of knowledge about antibiotic resistance. 
Although not significant, the results showed that respondents who reported low susceptibility of developing a condition related to antibiotic resistance had higher odds of practicing self- medication with antibiotics (OR = 1.32 95\% Cl: 0.488-3.559) compared to respondents with high susceptibility. However, respondents who perceived high severity of a disease associated with antibiotics resistance were found to have significantly lower odds of practicing self- medication with antibiotics ( $\mathrm{OR}=0.128,95 \% \mathrm{Cl}$ : $0.046-0.357)$ compared to respondents who perceived low severity of disease.

Table 6

Logistic Regression Model for factors associated with self-medication $(n=167)$

\begin{tabular}{|c|c|c|}
\hline Variable & $\begin{array}{l}\text { Crude OR } \\
(95 \% \mathrm{Cl})\end{array}$ & $\begin{array}{l}\text { Adjusted OR } \\
(95 \% \mathrm{Cl})\end{array}$ \\
\hline \multicolumn{3}{|l|}{ Age (years) } \\
\hline $18-24$ & $0.40(0.151-1.090)$ & $0.386(0.127-1.178)$ \\
\hline $25-34$ & $1.56(0.459-4.898)$ & $1.45(0.257-8.249)$ \\
\hline $35-44$ & $0.64(0.137-2.973)$ & $0.52(0.050-5.526)$ \\
\hline $45-54$ & Ref & Ref \\
\hline \multicolumn{3}{|l|}{ Gender } \\
\hline Male & $0.965(0.472-1.972)$ & $0.99(0.402-2.466)$ \\
\hline Female & Ref & Ref \\
\hline \multicolumn{3}{|l|}{ Duration of work } \\
\hline$\leq 5$ years & Ref & Ref \\
\hline$>5$ years & $0.39(0.191-0.833)$ * & $0.207(0.061-0.708)$ * \\
\hline \multicolumn{3}{|c|}{ Knowledge of antibiotic resistance } \\
\hline Low level of knowledge & Ref & Ref \\
\hline High level of knowledge & $0.196(0.077-0.502)$ * & $0.178(0.060-528)$ * \\
\hline \multicolumn{3}{|c|}{ Perceived susceptibility of ABR } \\
\hline Low susceptibility & $1.78(0.891-3.892)$ & $1.32(0.488-3.559)$ \\
\hline High susceptibility & Ref & Ref \\
\hline \multicolumn{3}{|c|}{ Perceived severity of disease with ABR } \\
\hline Low severity of disease & Ref & Ref \\
\hline High severity of disease & $0.206(0.092-0.459)$ * & $0.128(0.046-0.357)$ * \\
\hline
\end{tabular}




\section{Discussion}

This study provides a snapshot of the practice of antibiotic self-medication among nurses in a tertiary healthcare facility in Northern Ghana. Our study established that $77.1 \%$ of study participants recalled having practised self-medication with antibiotics of within 12 months and longer. This finding is relatively comparable with findings of similar studies conducted in Utter Pradesh and Mumbai, India. However, the observed results are higher than prevalence reported from Karad India and Ethiopia. It is also comparable with findings among other health professionals such as pharmacists in Malaysia, dentists in India, junior doctors in Norway and staff pharmacists in Russia.

The difference between the prevalence rates reported from different countries might be due to many factors, such as differences in study designs, healthcare systems, legislations, and socio- demographic characteristics of the study populations involved. The extent and reasons for self- medication with antibiotics might differ contextually due to different study methodologies and variations in the socio-demographic characteristics of respondents. For instance, variations in income among nurses and availability of social health insurance policies could be possible contributory factors to the different prevalence rates being observed.

Furthermore, differences in terms of accessibility to antibiotics and variations in level of knowledge of antibiotics treatment options might also explain the difference in prevalence rates. Studies by Sado et al. and Pankaj et al. further provide some evidence to support this assertion. To further support this claim, the Structural Model of Health behaviour emphasises on factors such as availability/accessibility, physical structures, and social structures to influence health behaviour. Therefore, the impact of these factors on health behaviour in different contexts results in the variations of prevalence of self- medication with antibiotics. Also, differences in structural factors in the implementation of regulatory policies regarding purchase and use of antibiotics among countries especially in LMICs might contribute greatly to the differences in prevalence. Due to the variations in these studies, the results are difficult to compare. Nevertheless, the present study contributes further evidence that self-medication with antibiotics is a widespread global phenomenon that requires coordinated efforts to mitigate inappropriate use of antibiotics and its attendant consequences.

Findings of the multivariable logistic regression analysis showed that gender was not significantly associated with self-medication with antibiotics in this study. This finding is in accordance with the findings on health care workers from other African countries, such as Ethiopia and Asian countries, such as India and among the general population in Pakistan. However, the result was found to be inconsistent with the findings observed in Guatemala where women were found to practise self-medication with antibiotics more than men. The absence of gender difference in terms of self-medication among participants might be due to participants' exposure to the same factors such as working environment, accessibility to antibiotics, knowledge of antibiotics etc.

Furthermore, this study also assessed the relationship between years of work after completing nursing school and self-medication with antibiotics. The study showed that respondents with $>5$ years of work experience were less likely to practice self-medication compared to respondents with work experience of $\leq 5 \mathrm{years}$. This 
finding is also consistent with the results of a study conducted in Ethiopia. The reason could be that respondents with less experience might not be aware that they are lacking knowledge and be overconfident about their own ability to decide about the appropriateness of treatment whereas more experienced nurses might have had more opportunity to witness the consequences of antibiotic resistance.

The role of knowledge of antibiotic resistance in relation to self- medication with antibiotics among study participants was also assessed in this study. Overall analysis of knowledge showed that participants with high level of knowledge about antibiotic resistance have lower odds of practicing self-medication with antibiotics compared to respondents with a low level of knowledge about antibiotic resistance.

Comparatively, this finding is in line with the results observed among the general population in Pakistan and South Africa. Good knowledge of antibiotic resistance could decrease the chances of practicing selfmedication with antibiotics which might be due to having an informed knowledge about the repercussions of antibiotic resistance.

The study also assessed perceived personal susceptibility of developing a condition with antibiotic resistance and the severity of such a condition among study participants and how this influenced selfmedication with antibiotics.

The study showed no significant association between self-medication and the perceived likelihood of oneself developing a condition with antibiotic resistance. However, respondents who perceived high severity of a condition with antibiotic resistance had lower chances of using antibiotics without prescription. This finding is in line with the results observed in Iran. The findings imply further intervention efforts are needed to create awareness about the repercussions of antibiotic resistance such as misdiagnoses, increased severity of disease prolong hospitalisation and increase health care costs which could help to curtail practices that lead to bacterial resistance such as inappropriate use of antibiotics.

Limitations of the study

The study was based on a cross-sectional survey design, that is the data on self-medication practices and associated factors were collected simultaneously making temporal relationships (cause-effect) non-existent. The study might be limited by recall bias since a recall period of 12 months or longer was used to collect data. In addition, even though the questionnaire was anonymous, it cannot be entirely excluded that social desirability of the study participants played a role. This study was also carried out in a specific context, a teaching hospital in Ghana involving only nurses as participants. Therefore, generalisation of the findings should be made with caution. More studies in different settings and study designs would be necessary to confirm or refute the findings.

\section{Conclusion}

This study has shown that the use of antibiotics without prescription is highly prevalent among the study participants though majority are aware that self-medication with antibiotics could lead to the development of antibiotic resistance. The medical store or pharmacy was the main source of obtaining antibiotics by study participants without prescription. We observed that social dynamics permitting the interaction between 
nurses and pharmacists could play a role in the accessibility of antibiotics from the pharmacy without a prescription. While there is the need to promote education on antibiotic use and control of bacterial resistance among nurses and stronger enforcement of the laws which forbid sales without prescription, further studies investigating the role of social dynamics in self-medication with antibiotics among nurses is recommended.

\section{Abbreviations}

OTC: Over the Counter; LMICs: Low-and Middle-income Countries; HICs: High-income Countries; SDGs: Sustainable Development Goals; ABR: Antibiotic Resistance; WHO: World Health Organization; UDS: University for Development Studies; USA: United States of America; SPSS: Statistical Package for the Social Sciences; $\chi 2$ : Chi-Square; OR: Odd Ratio; Cl: Confidence Intervals

\section{Declarations}

\section{Availability of data and materials}

The datasets used and/or analyzed during the current study are available from the corresponding author on reasonable request.

\section{Competing Interests}

The authors declare that they have no competing interests.

\section{Funding}

No funding or sponsorship was allocated to this study or publication of this article.

\section{Author contributions}

I.N.I. conceived the idea of the cross-sectional study. I.N.I. and RAS conducted the data collection and analysis,

F.O.A. and I.N.I. drafted the initial manuscript and contributed to writing the manuscript.

\section{Acknowledgements}

This article is a part of a Master of Science in public health thesis. My profound gratitude goes to Professor Anja Leppin, Unit for Health Promotion Research, University of Southern Denmark, Odense, Denmark who supervised the thesis work. Many thanks go to the management and staff of the Tamale Teaching Hospital for the permission and support to conduct the study.

\section{References}

Abdulraheem, Ibraheem, Adeoye Adegboye, and Akin Fatiregun. "Self-medication with Antibiotics: Empirical Evidence from a Nigerian Rural Population." (2016). 
Ali, Akbar Shoukat, Javed Ahmed, Gomand Beekho Sonekhi, Nargis Fayyaz, Zeeshan Zainulabdin, and Rahim Jindani. "Practices of self-medication with antibiotics among nursing students of Institute of Nursing, Dow University of Health Sciences, Karachi, Pakistan." JPMA. The Journal of the Pakistan Medical Association 66, no. 2 (2016): 235-237. https://europepmc.org/article/med/26819180.

Alghadeer, Sultan, Khalid Aljuaydi, Salmeen Babelghaith, Abdullah Alhammad, and Mohammed N. Alarifi. "Self-medication with antibiotics in Saudi Arabia." Saudi pharmaceutical journal 26, no. 5 (2018): 719-724. https://doi.org/10.1016/j.jsps.2018.02.018.

Becker, M. H. The Health Belief Model and personal health behaviour. Health Education Monographs, no. 2, (1974), 324-508.

Belkina, Tatiana, Natalia Duvanova, Julia Karbovskaja, Jurjen Duintjer Tebbens, and Jiri Vlcek. "Antibiotic use practices of pharmacy staff: a cross-sectional study in Saint Petersburg, the Russian Federation." BMC Pharmacology and Toxicology 18, no. 1 (2017): 1-6.

https://bmcpharmacoltoxicol.biomedcentral.com/articles/10.1186/s40360-017-0116-y.

Bilal, Muhammad, Abdul Haseeb, Mohammad Hassaan Khan, Mohammad Hussham Arshad, Asma Akbar Ladak, Sufyan Khan Niazi, Muhammad Daniyal Musharraf, and Adil Al-Karim Manji. "Self-medication with antibiotics among people dwelling in rural areas of Sindh." Journal of clinical and diagnostic research: JCDR 10, no. 5 (2016): OC08. https://www.ncbi.nlm.nih.gov/pmc/articles/PMC4948439/.

Biswas, Suvadip, A. Ghosh, K. Mondal, S. Dalui, M. Haldar, and S. Biswas. "Self-medication with antibiotics among undergraduate nursing students of a government medical college in Eastern India." IJPR 5, no. 10 (2015): 239-43.

Boateng, D. P., "Self-medication among doctors and pharmacists at the Korle Bu Teaching Hospita"l: Department of Clinical and Social Pharmacy, Kwame Nkrumah University of Science and Technology, 2009. 
Chalker, John. "Improving antibiotic prescribing in Hai Phong Province, Viet Nam: the" antibiotic-dose" indicator." Bulletin of the World Health Organization 79 (2001): 313-320.

https://www.scielosp.org/article/bwho/2001.v79n4/313-320/.

Cohen, Deborah A., Richard A. Scribner, and Thomas A. Farley. "A structural model of health behavior: a pragmatic approach to explain and influence health behaviors at the population level." Preventive medicine 30, no. 2 (2000): 146-154. https://doi.org/10.1006/pmed.1999.0609.

Donkor, Gracious Yoofi, Ebenezer Dontoh, and Alex Owusu-Ofori. "A cross-sectional study on the prevalence of antibiotic use prior to laboratory tests at two Ghanaian hospitals." PloS one 14, no. 1 (2019): e0210716. https://doi.org/10.1371/journal.pone.0210716.

Fekadu, Ginenus, Dinka Dugassa, Getandale Zeleke Negera, Tilahun Bakala Woyessa, Ebisa Turi, Tadesse Tolossa, Getahun Fetensa, Lemessa Assefa, Motuma Getachew, and Tesfaye Shibiru. "Self-medication practices and associated factors among health-care professionals in selected hospitals of western Ethiopia." Patient preference and adherence 14 (2020): 353. Doi: 10.2147/PPA.S244163

Gala, Khushboo S., Shyamal R. Sinha, Mankeshwar Ranjit, Viral K. Desai, and Ritu S. Gala. "Evaluation of the pattern of self-medication among the paramedical support staff in a tertiary care hospital." Journal of Young Pharmacists 8, no. 1 (2016): 23. DOI:10.5530/jyp.2016.1.6.

Gholap, Manisha C., and Vaishali R. Mohite. "Assess the self medication practices among staff nurses." Indian Journal of Scientific Research (2013): 81-85. https://go.gale.com/ps/anonymous? id=GALE\%7CA347405683\&sid=googleScholar\&v=2.1\&it=r\&linkaccess=abs\&issn=09762876\&p=AONE\&sw=w.

Grigoryan, Larissa, Dominique L. Monnet, Flora M. Haaijer-Ruskamp, Marc JM Bonten, Stalsby Lundborg, and Theo JM Verheij. "Self-medication with antibiotics in Europe: a case for action." Current drug safety 5, no. 4 (2010): 329-332. DOl: https://doi.org/10.2174/157488610792246046.

Haque, M., Rahman, N. A. A., Mckimm, J., Kibria, G. M., Azim Majumder, M. A., Haque, S. Z., Islam, M. Z., Binti Abdullah, S. L., Daher, A. M., Zulkifli, Z., Rahman, S., Kabir, R., Lutfi, S. \& Aishah Binti Othman, N. S.. Self- 
medication of antibiotics: investigating practice among university students at the Malaysian National Defence University. Infect Drug Resist, no. 12,(2019), 1333-1351.

Hem, Erlend, Guro Stokke, Reidar Tyssen, Nina T. Grønvold, Per Vaglum, and Øivind Ekeberg. "Self-prescribing among young Norwegian doctors: a nine-year follow-up study of a nationwide sample." BMC medicine 3, no. 1 (2005): 1-7. https://bmcmedicine.biomedcentral.com/articles/10.1186/1741-7015-3-16.

Holmes, King K., Stefano Bertozzi, Barry R. Bloom, Prabhat Jha, Hellen Gelband, Lisa M. DeMaria, and Susan Horton. "Major infectious diseases: key messages from disease control priorities." (2017): 1-27. https://doi.org/10.1596/978-1-4648-0524-0_ch1.

Jalilian, Farzad, S. M. Mehdi Hazavehei, Ali Asghar Vahidinia, Mohsen Jalilian, and A. Moghimbeig. "Prevalence and related factors for choosing self-medication among pharmacies visitors based on health belief model in Hamadan Province, west of Iran." Journal of research in health sciences 13, no. 1 (2013): 81 85. ISSN 16822765.

Kalungia, Aubrey Chichonyi, Johanita Burger, Brian Godman, Juliana de Oliveira Costa, and Chimwemwe Simuwelu. "Non-prescription sale and dispensing of antibiotics in community pharmacies in Zambia." Expert review of anti-infective therapy 14, no. 12 (2016): 1215-1223.

https://doi.org/10.1080/14787210.2016.1227702.

Lei, Xiaosheng, Heng Jiang, Chaojie Liu, Adamm Ferrier, and Janette Mugavin. "Self-medication practice and associated factors among residents in Wuhan, China." International journal of environmental research and public health 15, no. 1 (2018): 68. https://doi.org/10.3390/ijerph15010068.

Mensah, Barbara Nyantakyiwah, Irene Bonewa Agyemang, Daniel Kwame Afriyie, and Seth Kwabena Amponsah. "Self-medication practice in Akuse, a rural setting in Ghana." Nigerian Postgraduate Medical Journal 26, no. 3 (2019): 189. https://www.npmj.org/article.asp?issn=11171936; year=2019; volume=26;issue=3;spage=189;epage=194; ;ulast=Mensah.

Michael, Carolyn Anne, Dale Dominey-Howes, and Maurizio Labbate. "The antimicrobial resistance crisis: causes, consequences, and management." Frontiers in public health 2 (2014): 145. 
O'Neill, Jim. "Tackling drug-resistant infections globally: final report and recommendations." (2016). https://apo.org.au/node/63983.

Pankaj C.K., Arvind M. K., Atul J., Neha S., Ajitesh M.. Self-Medication Practices with Antibiotics Among Health Care Professional in Uttar Pradesh, India: "A Questionnaire Based Study". Indo American Journal of Pharm Research, no. 2, (2015).

Ramay, Brooke M., Paola Lambour, and Alejandro Cerón. "Comparing antibiotic self-medication in two socioeconomic groups in Guatemala City: a descriptive cross-sectional study." BMC Pharmacology and Toxicology 16, no. 1 (2015): 1-8. https://link.springer.com/article/10.1186/s40360-015-0011-3.

Ramchurren, K., Y. Balakrishna, and S. Mahomed. "Patients' knowledge, attitudes and practices regarding antibiotic use at a regional hospital in KwaZulu-Natal, South Africa 2017." Southern African Journal of Infectious Diseases 33, no. 5 (2018): 1-6. https://doi.org/10.1080/23120053.2018.1516393.

Sado, Edao, Endashaw Kassahun, Getu Bayisa, Mohammed Gebre, Ayana Tadesse, and Balisa Mosisa. "Epidemiology of self-medication with modern medicines among health care professionals in Nekemte town, western Ethiopia." BMC research notes 10, no. 1 (2017): 1-5. https://bmcresnotes.biomedcentral.com/articles/10.1186/s13104-017-2865-5

Shehab, Nadine, Priti R. Patel, Arjun Srinivasan, and Daniel S. Budnitz. "Emergency department visits for antibiotic-associated adverse events." Clinical infectious diseases 47, no. 6 (2008): 735-743. https://doi.org/10.1086/591126.

Shubha, R., Madhav K. Savkar, and G. N. Manjunath. "Self medication pattern among dentists with antibiotics." Journal of Evolution of Medical and Dental Sciences 2, no. 46 (2013): 9037-9042. link.gale.com/apps/doc/A362963028/HRCA?u=anon ac4fb4f3\&sid=googleScholar\&xid=82bf01c9. 
Sunny, Tittu Pulikkottil, Rosmin Jacob, K. Krishnakumar, and Sachin Varghese. "Self-medication: Is a serious challenge to control antibiotic resistance?." National Journal of Physiology, Pharmacy and Pharmacology 9 , no. 9 (2019): 821-827. http://www.njppp.com/fulltext/28-1559581707.pdf.

Sigaúque, B., and E. Sevene. "Situations analysis and recomendations: Antibiotic use and resistance in Mozambique." The Garp Mozambique working group. The center for disease dynamic, economics and policy, Washington DC and New Delhi (2015). http://www.who.int/ mediacentre/news/releases/2014/amrreport/en/.

Soroush, Ali, Alireza Abdi, Bahare Andayeshgar, Afsoon Vahdat, and Alireza Khatony. "Exploring the perceived factors that affect self-medication among nursing students: a qualitative study." BMC nursing 17, no. 1 (2018): 1-7. https://bmcnurs.biomedcentral.com/articles/10.1186/s12912-018-0302-2.

Tangcharoensathien, Viroj, Sunicha Chanvatik, and Angkana Sommanustweechai. "Complex determinants of inappropriate use of antibiotics." Bulletin of the World Health Organization 96, no. 2 (2018): 141. Doi: 10.2471/BLT.17.199687

Torres, N. F., B. Chibi, L. E. Middleton, V. P. Solomon, and T. P. Mashamba-Thompson. "Evidence of factors influencing self-medication with antibiotics in low and middle-income countries: a systematic scoping review." Public health 168 (2019): 92-101. https://doi.org/10.1016/j.puhe.2018.11.018.

United Nations. Sustainable Development Goals. (Online), (2017), https://unstats.un.org/sdgs/indicators/indicators-list/.

Williams, Allison, and Kimberley Crawford. "Self-medication practices among undergraduate nursing and midwifery students in Australia: a cross-sectional study." Contemporary nurse 52, no. 4 (2016): 410-420. https://doi.org/10.1080/10376178.2016.1197782

World Health Organization. Sampling methods and sample size. In: Omi S, editor. Health research methodology. A guide for training in research methods. 2nd ed, (2001). 
World Health Organization. "Antibiotic resistance: Multi-country public awareness survey." (2015). https://apps.who.int/iris/bitstream/handle/10665/194460/9789241509817_eng.pdf.

World Health Organization. Global priority list of antibiotic-resistant bacteria to guide research, discovery and development of new antibiotics, 2017.

\section{Figures}

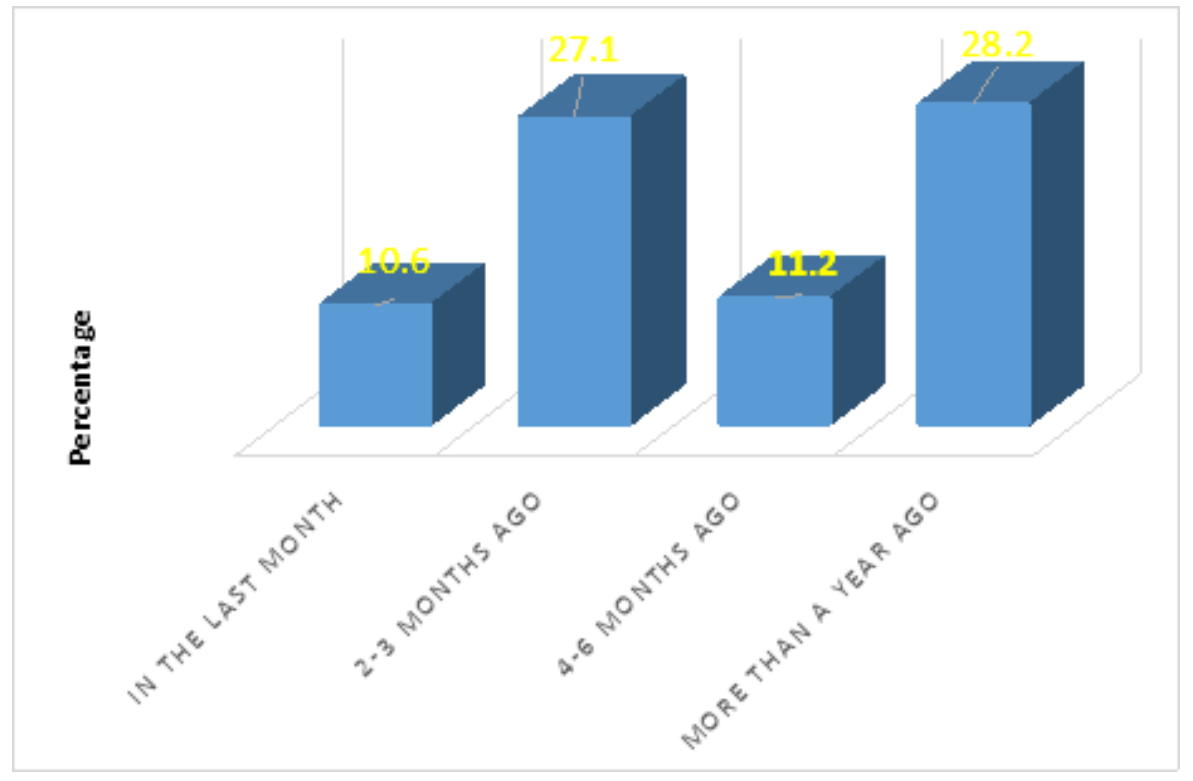

\section{Figure 1}

Last time of self-medication with antibiotics (\%) 


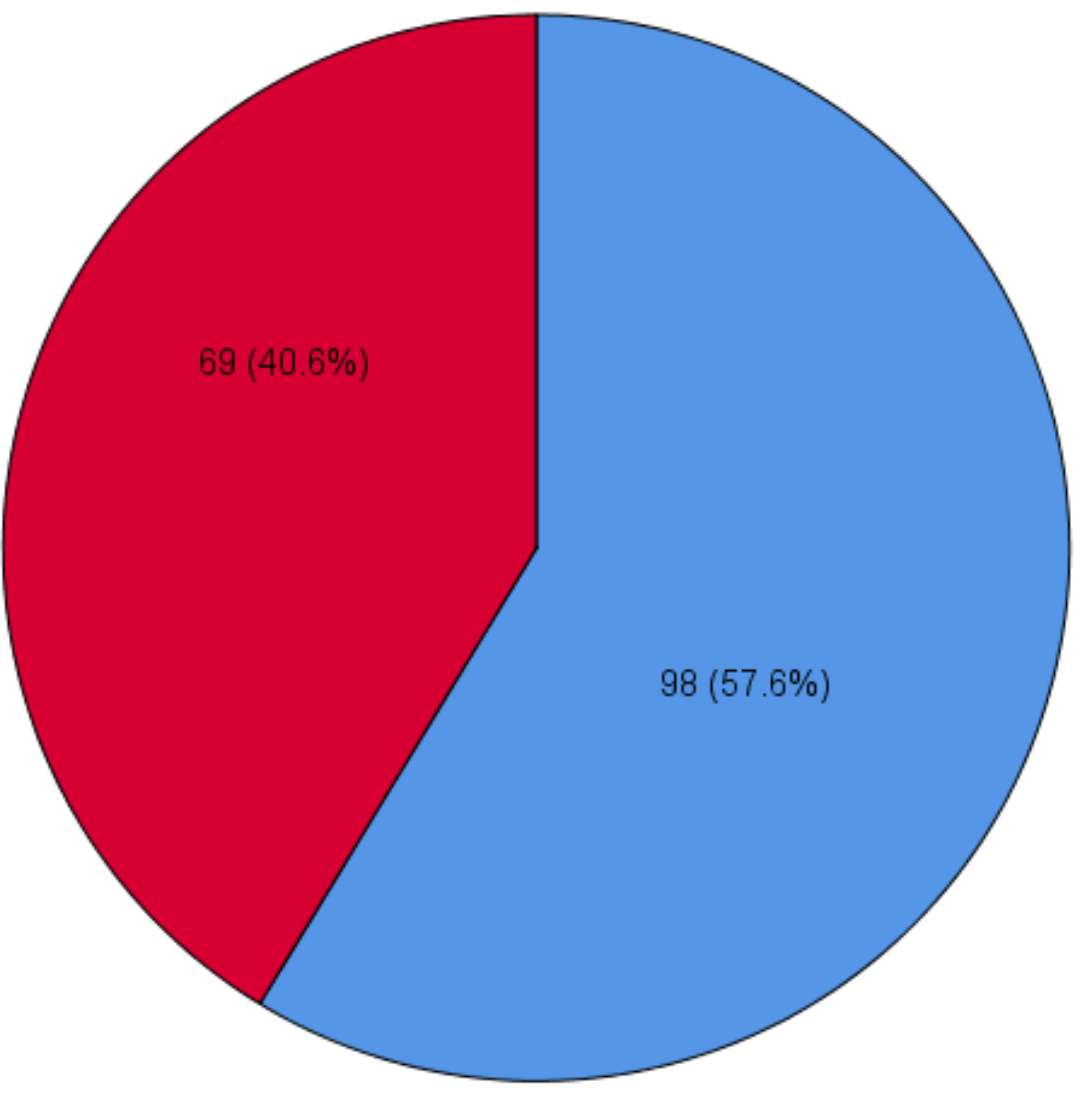

$\square$ Low level of knowledge

High level of knowlege

\section{Figure 2}

Level of knowledge about antibiotic resistance among respondents $(\%),(n=167)$

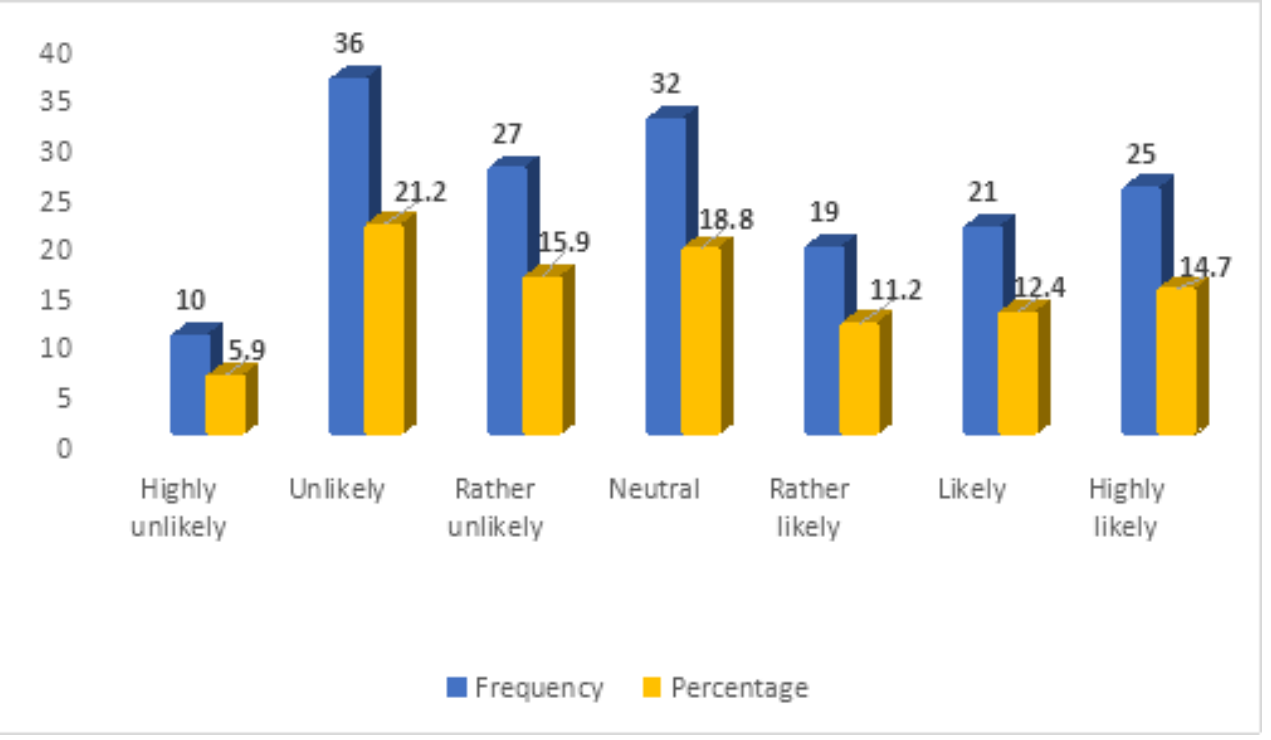

Figure 3 
Likelihood of developing condition with antibiotic resistance

80

70

60

50

40

30

20

10

0

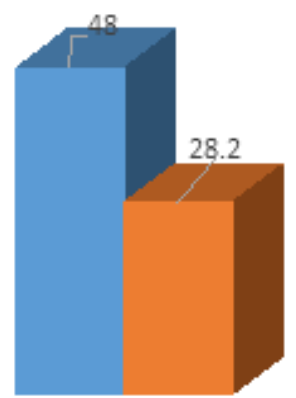

Not severe at all

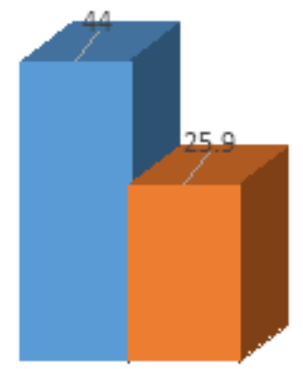

Medium severe

- Frequency $\quad$ Percent

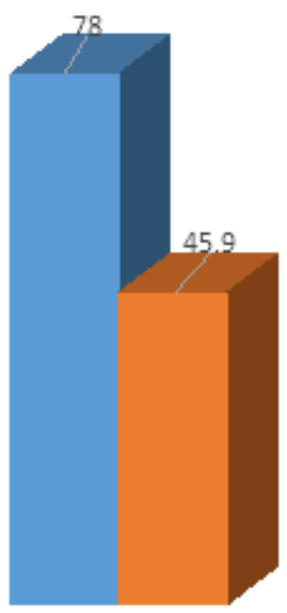

Very severe

\section{Figure 4}

Severity of developing a condition with antibiotic resistance

\section{Supplementary Files}

This is a list of supplementary files associated with this preprint. Click to download.

- Additionalfile1.pdf 